\section{MODELING OF THE HEAT DISSIPATION PROCESS OF COMPOSITE MATERIALS DURING STABILIZATION OF THE STRUCTURE USING THE EXAMPLE OF NON- AUTOCLAVED FOAM CONCRETE}

\author{
SERGEY V. FEDOSOV ${ }^{1}$, KSENIIA L. DOMNINA ${ }^{2}$, MAROS \\ SOLDAN ${ }^{3 *}$, MAXIM O. BAKANOV
}

${ }^{1}$ Department of technology of binders and concretes, Moscow State (National Research) University of Civil Engineering, Volga

State University of Technology, Russian Academy of Architecture and Building Sciences, Moscow, Russia.

${ }^{2}$ Votkinsk branch of Kalashnikov Izhevsk State Technical University, Russia

${ }^{3}$ Institute of Integrated Safety, Slovak Technical University in Bratislava, Faculty of Materials Science and Technology in Trnava, Trnava, Slovakia, ${ }^{4}$ Department of fire tactics and the basics of rescue and other emergency operations, Ivanovo Fire Rescue Academy of State Firefighting Service of Ministry of Russian Federation for Civil Defense, Ivanovo, Russia;

\section{DOI: 10.17973/MMSJ.2020_10_2020061}

e-mail: maros.soldan@stuba.sk

\begin{abstract}
The article presents the features of mathematical modeling of the heat release during hardening of composite cellular materials using the example of non-autoclaved foam concrete. The reactions of hardening and structure formation in foam concrete are exothermic and are called hydration reactions. The article lists the technological factors affecting the heat release during hydration. The basis for research and modeling of thermal processes in the structure formation of cellular composite materials is the nonlinear differential equation of non-stationary thermal conductivity with a source distributed over coordinate space and time. At the first stages of modeling it is advisable to set the boundary conditions and solve a plane problem for one of the coordinates. The mathematical description of the kinetics of heat release of the hydration reaction is presented for an elementary foam concrete sample with a face size of $L$ centimeters. Heat transfer in all directions in the sample is similar due to the ordered cellular structure. As a result, the equations describing the heat release during the hydration of foam concrete along any one axis are obtained. This allows us to determine the course of the heat release process and the temperature distribution at any point in the volume of the composite material.
\end{abstract}

Keywords: cellular composite, foam concrete, heat release, hydration, heat and mass transfer

\section{INTRODUCTION}

Before setting gas-filled composites are three-phase systems that consist of solid $(S)$, liquid $(L)$ and gaseous $(G)$ phases. As a rule the finished material consists of two structure-forming elements: Solid-Gaseous [Kar 2017].

The most common composite with a gas-filled porous structure is cellular concrete. The most popular of this group is non-autoclaved foam concrete due to lower capital investments in the organization of production, as well as a simpler manufacturing technology [Struharova 2007], [Pustylnik 2017]. Physical and chemical processes that occur during the interaction of portland cement with water, lead to the formation of a cement stone of interstitial partitions.

The adsorption of the foaming agent at the phase boundaries of Gaseous-Liquid and Liquid-Solid, as well as the film character of the condensed medium, additionally affect the classical structure formation during cement hardening in foam concrete.

In the literature [Kim 2010], [Wang 2019] the entire complex of physical and chemical processes leading to the hardening of cement slurry is called hydration reactions. The hydration reactions of portland cement are exothermic, i.e. they occur with the release of heat. The total heat of hydration is the sum of the individual thermal effects such as [Schutter 1995]:

- heat of wetting powdered substances with water;

- heat of dissolution of cement minerals in water

- heat of chemical reactions of joining water to form hydrates (chemical heat of hydration of the binder);

- heat of crystallization of other phase transitions occurring in the hardening cement stone;

- heat of adsorption of water in the hydration products.

In the experimental determination of heat release, the total heat effect of the above components is found, and the most significant is the third term.

The mechanism of the hydration reaction and the rate of its course change in time. It can be judged by the kinetics of heat release of the process. Soviet scientist A. UsherovMarshak identifies the following characteristic periods of hydration of portland cement in the early stages of hardening (fig. 1) [Usherov-Marshak 2002].

Heat release begins immediately after the cement is mixed with water and is explained by the wetting effect. This is marked by the first peak in graph 1 . This stage is characterized by an irregular change in the rate of the heat release process. The rate of the process drops from maximum to minimum within a few minutes. The maximum temperature values are reached 14-18 hours after the start of hardening. This is the second peak. Subsequently, a smooth decrease in the rate of the process is observed. 

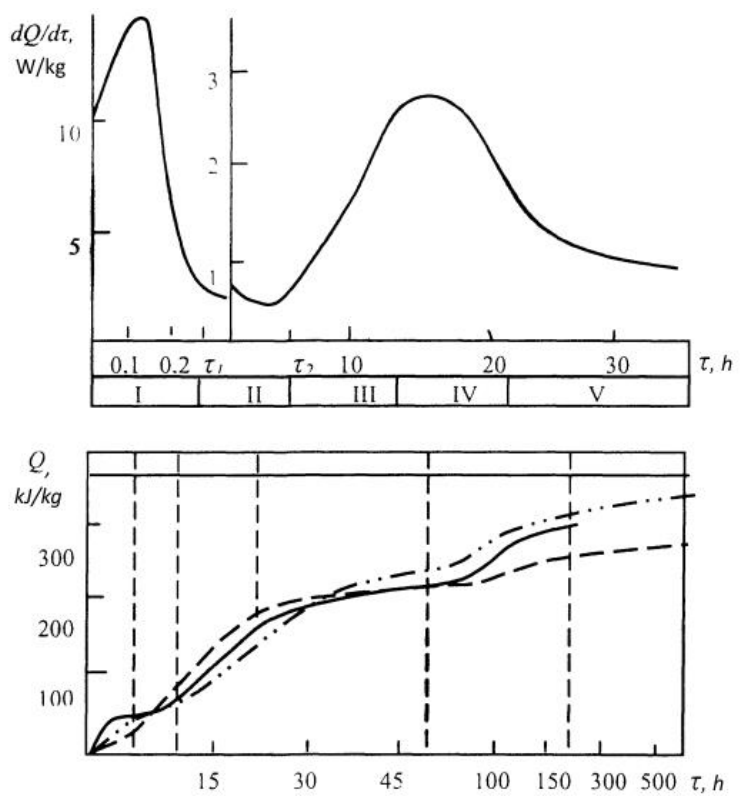

Figure 1. Kinetics of heat release during hydration of portland cement: specific periods and forecast of heat release: I - initial; II - induction; III - accelerated; IV - delayed; V - monotonic decay

\section{TECHNOLOGICAL FACTORS AFFECTING HEAT RELEASE DURING HYDRATION}

The parameters of heat release, such as the total heat effect and the rate at various stages of hydration, reflect the influence of technological factors with sufficient completeness. These factors are divided into external and internal. External factors include temperature, humidity, ambient pressure, conditions of heat and mass transfer of concrete with the environment, etc. Internal factors are the chemical, mineralogical and granulometric composition of cement, the water-cement ratio, the geometry and volume of the array, the type and amount of aggregate, the presence of additives that regulate the hardening process and material properties, etc.

Heat release is an additive property in relation to the individual cement components, namely to the main clinker minerals. They are tricalcium silicate $C_{3} S$, dicalcium silicate $C_{2} S$, tricalcium aluminate $C_{3} A$ and tetra calcium aluminoferrite $C_{4} A F$. The influence of the mineralogical composition of clinker on the amount of heat release is due to the fact that different minerals, when fully hydrated, have different thermochemical effects and are characterized by different rates of interaction with water. According to the amount of heat release and the nature of its development in time, clinker minerals are arranged in a row: $C_{3} A>C_{3} S>C_{4} A F>C_{2} S$.

The heat of hydration of cement is an additive property, so it can be predicted from an expression like [Mehta 2006]:

$H=a \cdot C_{3} S+b \cdot C_{2} S+c \cdot C_{3} A+d \cdot C_{4} A F ，$

where $H$ is the specific heat release of cement; $C_{3} S, C_{2} S$, $C_{3} A, C_{4} A F$ are the content of clinker minerals in cement, \%; $a, b$, $c, d$ are the coefficients representing the proportions of mineral content. The values of the coefficients will differ for the various periods of hydration.

The use of the equation (1) in predicting the heat release of cements is rarely encountered in practice. This is due to the fact that this equation is valid only for non-additive cements.

Russian researcher $\mathrm{V}$. Babitskiy received a relationship linking the specific heat release of cement $\left(q_{c}, k J / k g\right)$ with the value of the current degree of its hydration $\left(\alpha_{\tau}, \%\right)$ at a specific stage of concrete hardening, based on the equation (1) [Babitsky 2005]

$q_{\mathrm{c}}=4,19 \cdot\left(0,01668 \cdot \mathrm{C}_{3} \mathrm{~S}+0,00251 \cdot \mathrm{C}_{2} \mathrm{~S}+0,02808 \cdot \mathrm{C}_{3} \mathrm{~A}+0,00238 \cdot \mathrm{C}_{4} \mathrm{AF}\right) \cdot \alpha_{\tau}$,

where 4,19 is the conversion factor from $\mathrm{kcal}$ to $\mathrm{kJ}$.

The equation (2) is more correct, because it contains a correction coefficient of the degree of hydration of the cement.

R. Carlson et al. have studied the influence of temperature, fineness of grinding and water-cement ratio on the heat release of cement [Carlson 1938], [Copeland, 1960], [Lerch 1934], [Raymond 1934], [Verbeck 1950]. They found that in the early stages of hydration, an increase in temperature, fineness of grinding and water-cement ratio lead to an increase in the rate of heat release. But their influence becomes less the more time has passed since the beginning of hydration.

The rate of hydration depends on the fineness of the portland cement grinding, because the hydration reaction starts from the surface of the cement particles. The finer grind provides a larger surface area for wetting, which leads to an accelerated reaction between cement and water. This increases the rate of heat release at an early age, but does not affect the total amount of heat released over a few weeks. However, the higher the fineness of cement grinding is, the faster it decreases its activity during storage in air and the more prone to cracking. It can be assumed that the rate of hydration is directly proportional to the specific surface area.

Temperature has an intense effect on the rate of hydration. With some reservations, it can be assumed that the dependence of the rate of hydration obeys the Arrhenius equation:

$\frac{d(\ln K)}{d T}=\frac{E}{R T^{2}}$,

where $K$ is the reaction rate constant; $T$ is temperature, $K ; E$ is the activation energy, $\mathrm{J} / \mathrm{mol} ; R$ is the universal gas constant: $R=8,314 \mathrm{~J} / \mathrm{K} \cdot \mathrm{mol}$.

I. Rakhimbayev found that with an increased watercement ratio, the induction period significantly increases too. At the same time, the stage of active cement hydration slows down and the intensity of the heat flow decreases, especially with the use of super plasticizer additives [Rakhimbayev 2012]. In turn, S. Mindess determined that a water-cement ratio of at least 0,4 is required for the complete hydration of cement in foam concrete [Mindess 2012].

The geometry and volume of the array also affect heat release during hydration. Significant heating of structures in the deep layers occurs during the construction of massive structures using heavy concrete. The surface of concrete arrays cools relatively quickly, but inside the array cooling is slow. As a result, a temperature difference is created between the internal and external parts of the structure, and tensile stresses arise, which can cause the formation of cracks. At the same time, the exothermic effect of small-sized concrete structures isn't taken into account, since its effect is insignificant. Heat is released into the surrounding space relatively quickly and does not cause a significant increase in temperature.

Sand and fly ash are most often used as an aggregate in the production of foam concrete. Both types of aggregates slow down the hydration reactions of portland cement, especially at an early stage. Increasing aggregate consumption also reduces the amount of heat generated [Najafi 2013].

The presence of even small amounts of dissolved substances in the mixing water can lead to a noticeable change in the rate of cement hydration and the course of the pore formation process in the hardening foam concrete system. However, in the range of working concentrations additives 
regardless of the type do not have a significant effect on the kinetics of hydration.

The hydration process also depends on environmental factors. Cement hydration at higher external temperatures and pressures accelerates at an early age, but then slows down [Kim 2010].

In practice, the hydration process isn't taken into account, which is absolutely unacceptable. The intensity of heat release and the heat of hydration at its different stages are important indicators of the completion of cement hardening processes. Heat release in the mass of hardening foam concrete causes both slow and fast processes of volumetric internal deformations with the appearance of residual stresses after the end of the active period of hydration. This is the reason for the appearance of microcracks and overstressed zones in the material. This leads to a decrease in wear and vibration resistance and bearing capacity of products. The rate and depth of hydration at an early age are of the greatest interest, because at this time significant structural changes occur, and the hardening conditions affect the rate of strength gain most of all.

\section{Theory of mathematical processes of heat transfer}

The theoretical basis for the study of heat and mass transfer processes as a result of high temperatures in the material and external temperature influences is the system of differential equations obtained by prof. A. Lykov [Lykov 1978]. A large number of works made by soviet and foreign researchers are devoted to the solution of heat conduction equations [Fedosov 1982], [Fedosov 1978]. Classical methods such as the separation of Fourier variables, the Green's function, the integral transformations in finite and infinite limits are widely used to solve heat transfer problems. Various numerical methods are used to solve nonlinear problems.

The basis for researching and modeling of thermal processes in the structure formation of cellular composite materials is the nonlinear differential equation of nonstationary thermal conductivity with a source distributed over coordinate space and time [Pivarciova 2017], [Fedosov 2010], [Cernecky 2007]:

$\rho(u, t) \cdot c(u, t) \frac{\partial t(x, y, z, \tau)}{\partial \tau}=\lambda(u, t) \cdot \nabla^{2} t(x, y, z, \tau)+q_{v}(x, y, z, \tau)$,

где $\rho(u, t), c(u, t), \lambda(u, t)$ - density, heat capacity, thermal conductivity, which generally depend on moisture content $u$ and temperature $t ; q_{v}(x, y, z, \tau)$ - volume density of the heat source.

In general, the boundary value problems of heat and mass transfer can be represented by nonlinear inhomogeneous partial differential equations of the parabolic type.

At the first stages of modeling it is advisable to set the boundary conditions and solve a plane problem for one of the coordinates [Fedosov 2019], [Fedosov 2017], [Fedosov 2018]:

$\rho c \frac{\partial t(x, \tau)}{\partial \tau}=\frac{\partial}{\partial x}\left[\lambda(t) \frac{\partial t(x, \tau)}{\partial x}\right]+q_{v}(\tau)$.

Let's express $q_{v}(\tau)$ from equation (5):

$q_{v}(\tau)=\rho c \frac{\partial t(x, \tau)}{\partial \tau}-\frac{\partial}{\partial x}\left[\lambda(t) \frac{\partial t(x, \tau)}{\partial x}\right]$.

\section{Mathematical description of the kinetics of heat release}

For a mathematical description of the kinetics of heat release during the hardening of the composite over the entire volume of the sample at any point, we present it in the following form (fig. 2)

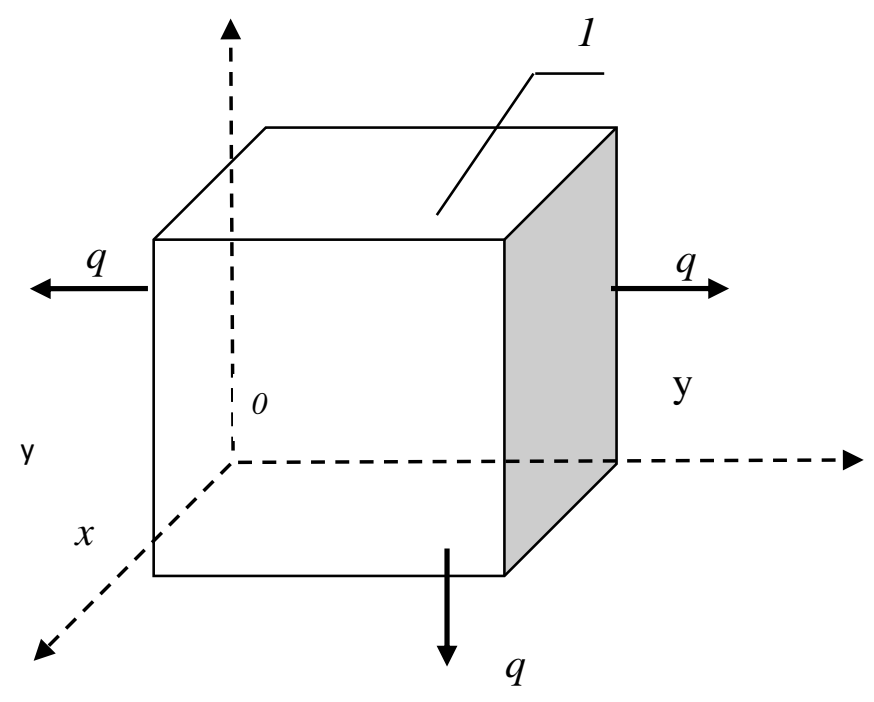

Figure 2. The model of a composite material with a porous structure: 1 - a composite

The process of heat release in all directions in the sample $(x-, y-, z$ - axes) is similar. Therefore, it is advisable to consider heat transfer along a single $x$-axis: $0 \leq x \leq L$ ( $L=H$ ) (fig. $3)$.

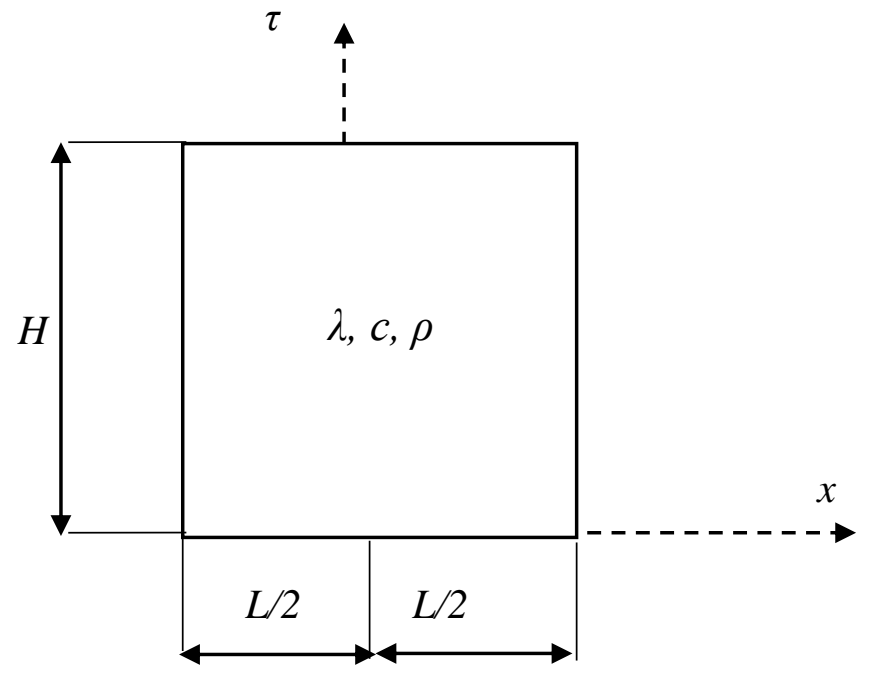

Figure 3. The geometric model of the composite sample used to pose the problem

The temperature distribution along the $x$-axis can be found from their comparison at the same time at the boundaries and in the center of the sample. Under these conditions, the boundary value problem of heat transfer is written as follows:

$$
\left.\begin{array}{l}
t(\tau, x=0)=t_{\text {border }}(\tau) \\
t(\tau, x=L / 2)=t_{\text {center }}(\tau) \\
t(\tau, x=L)=t_{\text {border }}(\tau)
\end{array}\right\}
$$


The distribution of temperature fields in the structure of the material during hardening of composites can be described by a parabolic law:

$$
t(x, \tau)=a x^{2}+b x+c,
$$

where $a, b, c$ are empirical dimensional coefficients.

Substituting the boundary conditions (7) into the equation (8), we obtain the dependence of the temperature in the sample on time and coordinates in a general form:

$$
\begin{aligned}
& t(x, \tau)= 40 x^{2}\left(t_{\text {center }}(\tau)-t_{\text {border }}(\tau)\right)-4 x\left(t_{\text {center }}(\tau)-t_{\text {border }}(\tau)\right)+t_{\text {center }}(\tau) \text {. } \\
& \text { Then the elements of the equation (6) will be }
\end{aligned}
$$
represented as:

$\frac{\partial t(x, \tau)}{\partial \tau}=40 x^{2}\left(\frac{\partial t_{\text {center }}(\tau)}{\partial \tau}-\frac{\partial t_{\text {border }}(\tau)}{\partial \tau}\right)-4 x\left(\frac{\partial t_{\text {center }}(\tau)}{\partial \tau}-\frac{\partial t_{\text {border }}(\tau)}{\partial \tau}\right)+\frac{\partial t_{\text {border }}(\tau)}{\partial \tau} ;$

$$
\frac{\partial}{\partial x}\left[\lambda(t) \frac{\partial t(x, \tau)}{\partial \tau}\right]=\frac{\partial}{\partial x}\left[\lambda(t) \cdot\left(80 x\left(t_{\text {center }}(\tau)-t_{\text {border }}(\tau)\right)+4\left(t_{\text {center }}(\tau)-t_{\text {border }}(\tau)\right)\right)\right]
$$

As a result, the equation (6) can be written as:

$$
\begin{aligned}
& q_{v}(\tau)=\rho c\left[40 x^{2}\left(\frac{\partial t_{\text {center }}(\tau)}{\partial \tau}-\frac{\partial t_{\text {border }}(\tau)}{\partial \tau}\right)-4 x\left(\frac{\partial t_{\text {center }}(\tau)}{\partial \tau}-\frac{\partial t_{\text {border }}(\tau)}{\partial \tau}\right)+\frac{\partial t_{\text {border }}(\tau)}{\partial \tau}\right]- \\
& -\left[\lambda(t) \cdot 80\left(t_{\text {center }}(\tau)-t_{\text {border }}(\tau)\right)\right]
\end{aligned}
$$

The equation (12) allows us to simulate the kinetics of heat release during hardening over the entire volume of a composite sample at any point. This will determine the progress of the process and the temperature distribution at each point of the sample volume.

\section{CONCLUSIONS}

An important role is played by the choice of the coordinate system in the modeling of thermal processes during the hardening of a composite material. Based on the statement of the problem, its solution as a whole depends on this. Currently, the attention of engineers and researchers is directed to mathematical modeling of various stages of technological processes in the production of different construction and heat-insulating materials. As noted in [Fedosov 2019], this goal can be achieved by considering and modeling the process as a complex production system, which consists of a finite set of technological subsystems with individual properties and characteristics. It becomes possible to regulate the process of obtaining materials at any stage of the production cycle with adequate models. The patterns of heat and substance transfer in composite materials are determined by the structural characteristics of the body. The complexity and diversity of the structure of a porous composite makes it necessary to create adequate mathematical models that can take into account both physical [Fedosov 2020] and thermal parameters [Pivarciova 2019] when producing this material at all stages of exposure to high temperatures. In the future, this will become possible due to the development of a method, based on a systematic approach, for taking into account the heat release of the hydration reaction during the hardening as part of the technological process for obtaining composites. It will be able to clarify the influence of the selected control factors for subsequent inclusion in the mathematical model of the technological process.

\section{ACKNOWLEDGEMENT}

This publication was written thanks to the support of the Ministry of Education, Science, Research and Sports of the Slovak Republic, the project support agency: project VEGA $1 / 0019 / 20$ "Accurate calculations, modeling and simulation of new surfaces based on physical causes of machined surfaces and additive technology surfaces in machinery and robotical machining conditions", project KEGA 013TUKE-4/2019 "Modern educational tools and methods for shaping creativity and increasing the practical skills and habits of graduates of technical departments of universities" and project KEGA 015STU-4/2018 „Specialised laboratory supported by multimedia textbook for subject "Production systems design and operation" for STU Bratislava".

\section{REFERENCES}

[Babitskiy 2005] Babitskiy, V.V. Prediction of the kinetics of concrete hardening during thermal holding of structures (Prognozirovaniye kinetiki tverdeniya betona pri termosnom vyderzhivanii konstruktsiy). Building materials, equipment, technologies of the XXI century. 2005, 4, pp. 66-67 (in Russ.)

[Carlson 1938] Carlson, R.W.; Forbrich, L.R. Correlation of Methods for Measuring Heat of Hydration of Cement. Industrial and Engineering Chemistry, Analytical Edition. 1938, 10, pp. 382-386

[Cernecky 2007] Cernecky, J.; Pivarciova, E. Possibilities and prospects of holography. Izhevsk State Technical University, Russia, 2007.

[Copeland 1960] Copeland, L.E.; Kantro, D.L.; Verbeck, G.J. Chemistry of Hydration of Portland Cement. Bulletin 153, Reprinted from Chemistry of Cement. Proceedings of the Fourth International Symposium, 1960.

[Fedosov 2019] Fedosov S.; Domnina K.; Pivarciova E. The construction of the function of the ultimate goal of the technological process of non-autoclaved foam concrete obtaining. Acta Tecnología - International Scientific Journal about Technologies, 2019, 5(3), pp. 59-62.

[Fedosov 2010] Fedosov, S. Heat and mass transfer in the technological processes of the construction industry (Teplomassoperenos $\mathrm{v}$ tekhnologicheskikh protsessakh stroitelnoy industrii). Ivanovo, 2010 (in Russ.).

[Fedosov 1987] Fedosov, S. The heat treatment processes of dispersed materials with phase and thermal transformations (Protsessy termicheskoy obrabotki dispersnykh materialov $\mathrm{s}$ fazovymi i termicheskimi prevrashcheniyami). Thesis for the degree of Doctor of Technical Sciences, 1987 (in Russ.).

[Fedosov 2019] Fedosov, S.; Anisimov, S.; Sokolov, A. Methods of researching the non-stationary temperature field at external electrical heating of plug connections in reinforced concrete columns of precast-monolithic structures (part 1) (Metodika issledovaniya nestatsionarnogo temperaturnogo polya pri naruzhnom elektroprogreve shtepselnykh soyedineniy zhelezobetonnykh kolonn sborno-monolitnykh sooruzheniy (chast' 1)). Bulletin of Civil Engineers. 2019, 2(73), pp. 35-42 (in Russ.).

[Fedosov 1992] Fedosov, S.; Kiselnikov, V.; Shertaev, V. Application of methods of the theory of heat conduction for modeling processes of convective drying (Primeneniye metodov teorii teploprovodnosti dlya modelirovaniya protsessov konvektivnoy sushki). Gylym, Alma-Ata, 1992. ISBN 5-628-00586-x (in Russ.).

[Fedosov 2017] Fedosov, S.V.; Bakanov, M.O. Modeling of temperature field distribution of the foam glass batch in terms of thermal treatment of foam glass. International Journal for Computational Civil and Structural Engineering. 2017, 13, pp. 112-118. doi:10.22337 / 1524-5845-2017-13-3-112-118.

[Fedosov 2020] Fedosov, S.V.; Bakanov, M.O.; Nikishov, S.N. Parametric optimization of the thermal processing of foam glass on basis of heat transfer models. IOP Conf. Series: Materials Science and Engineering. 2020, 709. doi:10.1088/1757-899x/709/4/044047. 
[Fedosov 2018] Fedosov, S.V.; Nikishov, S.N.; Bakanov, M.O. Kinetics of cellular structure formation at thermal treatment processes simulation in the cellular glass technology. Materials Science Forum. 2018, 931, pp. 628-633. doi:10.4028/www.scientific.net/MSF.931.628.

[Kar 2017] Kar, K.K. Composite Materials: Processing, Applications, Characterizations. Springer: Kanpur, Uttar Pradesh, India, 2017. ISBN 978-3-662-49512-4.

[Kim 2010] Kim, S.G. Effect of heat generation from cement hydration on mass concrete placement. Graduate Theses and Dissertations. lowa State University: Ames, lowa, 2010.

[Lerch 1934] Lerch, W.; Bogue, R.H. Heat of Hydration of Portland Cement Pastes. J. Res. Nat. Bur. Stand, 1934, 10, pp. 645-664.

[Lykov 1978] Lykov, A. Heat and mass transfer (Teplomassoobmen). Energy, Moscow, 1978 (in Russ.).

Mehta, P.; Monteiro, P. Microstructure, Properties, and Materials. New York: McGraw-Hill, 2006.

[Miundess 2012] Mindess, S.; Francis Young, J.; Darwin D. Concrete. Second Edition. NJ : Pearson Education, Inc, 2012.

Najafi, Z.; Ahangari K. The Prediction of Concrete Temperature during Curing Using Regression and Artificial Neural Network. Journal of Engineering, 2013, pp. 1-5. doi:10.1155/2013/946829.

[Pivarciova 2019] Pivarciova, E., Bozek, P. Domnina, K., Sagova Z. Design of the construction and research of vibrations and heat transfer of mine workings. Acta Montanistica Slovaca Volume 24,2019 , number 1, pp. 15-24

[Pivarciova 2019] Pivarciova, E.; Bozek, P.; Domnina, K.; Skultety, E.; Fedosov, S. Interferometric Measurement of Heat Transfer above New Generation Foam Concrete. Measurement Science Review. 2019, 4, pp. 153-160. doi:10.2478/msr-20190021.

[Pustylnik 2017] Pustylnik, O. Problems and prospects for the production of high-quality foam concrete (Problemy perspektivy proizvodstva vysokokachestvennogo penobetona). The generation of the future: a look from young scientists: a collection of scientific articles of the 6th International Youth Scientific Conference. 2017, 3, pp. 217-221 (in Russ.).
[Rakhimbayev 2012] Rakhimbayev, I.Sh.; Serdyukova A.A. Influence of water-cement ratio on the kinetics of heat release of cements (Vliyaniye vodotsementnogo otnosheniya na kinetiku teplovydeleniya tsementov). Cement and its application. 2012, 3, pp. 123-126.

Raymond, E.; Davis, R.; Carlson, W.; Troxell, D.E.; Kelly, J.W. Cement investigations of Boulder Dam with the results up to the age of one year. Proc. Am. Concrete Inst., 1934, 30, pp. 485-497.

[Schutter 1995] Schutter, G.D.; Taerwe, L. Specific heat and thermal diffusivity of hardening concrete. Mag. Conc. Res. 1995, 47(172), 203-208. doi:10.1680/macr.1995.47.172.203.

[Struharova 2007] Struharova, A.; Rousekova, I. Porous structure of cellular concrete and its impact on selected physical-mechanical properties of cellular concrete. Slovak Journal of Civil Engineering. 2007, pp. 35-43.

[Usherov-Marshak 2002] Usherov-Marshak, A.V. Calorimetry of Cement and Concrete: Selected Works. Kharkov "Fakt", 2002.

[Verbeck 1950] Verbeck, G.J.; Foster C.W. Long-Time Study of Cement Performance in Concrete. Proc. Am. Soc. Test. Mater. Chapter 6, 1950, 50, 1 pp. 235-1257.

[Wang 2019] Wang, Sh.; Jian, L.; Shu, Zh.; Wang, J.; Hua, X.; Chen, L. Preparation, properties and hydration process of low temperature nano-composite cement slurry. Construction and Building Materials. 2019, 205, pp. 434-442, doi:10.1016/j.conbuildmat.2019.02.049.

\section{CONTACTS :}

prof. Ing. Maros Soldan, PhD.

Institute of Integrated Safety, Slovak Technical University in Bratislava, Faculty of Materials Science and Technology in Trnava, Jana Bottu 2781/25, 91724 Trnava, Slovakia e-mail: maros.soldan@stuba.sk Phone: +421906068 501 